\title{
Role of skin prick test and serological measurement of specific IgE in the diagnosis of occupational asthma resulting from exposure to vinyl sulphone reactive dyes
}

\author{
J W Park, C W Kim, K S Kim, S Y Choi, D B Kang, S H Ko, J U Won, J Y Yang, \\ C-S Hong
}

\begin{abstract}
Objectives-Some patients with occupational asthma resulting from exposure to reactive dyes have skin reactivity to the causative dyes and specific IgE to reactive dyes have been found in these patients. However, the usefulness of skin prick tests (SPTs) and serological measurement of specific IgE in screening, diagnosis, and monitoring the occupational asthma resulting from exposure to reactive dyes have not yet been assessed. In this study, the clinical validation of SPTs and measurement of specific IgE to vinyl sulphone reactive dyes by enzyme linked immunosorbent assay (ELISA) was evaluated.
\end{abstract}

Methods - 42 Patients with occupational asthma from reactive dyes (true positive group) were enrolled. In these the causative reactive dye was confirmed by bronchial challenge test. 93 Asymptomatic factory workers with negative challenge to the reactive dye (true negative group) and 16 unexposed controls with negative challenge to the reactive dye were also enrolled. Skin prick tests were done with $\mathbf{1 0}$ $\mathrm{mg} / \mathrm{ml}$ reactive dye in $0.4 \%$ phenol $/ 0.9 \%$ saline. IgE specific to reactive dye conjugated to human serum albumin (HSA) was measured with enzyme linked immunosorbent assays (ELISAs).

Results-None of the unexposed controls had a positive response to SPTs. The sensitivity $(76.2 \% v 53.7 \%)$, specificity $(91.4 \%$ $v 86.0 \%)$, positive predictive value $(80.0 \%$ $v 62.9 \%$ ), and negative predictive value $(89.5 \% v 80.8 \%)$ of SPTs were higher than those of ELISAs. The mean weal size of reaction to reactive dye was weakly correlated with the ELISA optical density of IgE to reactive dye conjugate in patients with occupational asthma from reactive dyes $(n=41, r=0.337, p<0.05)$. In four patients with occupational asthma from reactive dyes and eight control subjects exposed to reactive dye, IgE specific to reactive dye conjugated to HSA was detected with ELISA even though they showed negative skin reactivity. Six patients completely avoided the reactive dye for a mean (SD) $27.8(10.3)$ months, IgE specific to reactive dyes decreased in all six patients $(p<0.05)$ during this time.
Conclusions-Both SPTs and detection of IgE specific to reactive dye in serum samples could be valuable for screening, diagnosis, and monitoring occupational asthma resulting from exposure to reactive dyes. These two tests would complement each other.

(Occup Environ Med 2001;58:411-416)

Keywords: reactive dye; occupational asthma; skin prick test

Reactive dyes bind covalently to the hydroxyl groups on proteins, and acting as haptens, they can elicit occupational asthma in exposed workers. The presence of specific IgE and positive skin responses to the dyes in patients with occupational asthma resulting from exposure to reactive dyes suggest that the IgE mediated immune responses may play an important part in the pathogenesis of this disease. ${ }^{1-8}$ However, we are confronted by many kinds of reactive dyes with different reactive functional groups - such as monochlorotriazine, dichlorotriazine, monochlorodifluoropyrimidine, dichloropyridazinone, bromoacrylamide, and vinyl sulphone. The allergenicity of reactive dye carrier could be different according to the types of reactive dye, carrier, and the conditions at which the hapten conjugation process occurred. ${ }^{39}$ The clinical significance of skin prick tests (SPTs) and the serological measurement of specific IgE in screening, diagnosis, and monitoring the occupational asthma from reactive dyes might be influenced by these factors and they are not yet well evaluated. The specific inhalation tests in the laboratory are still considered to be the gold standard in the diagnosis of occupational asthma from exposure to reactive dyes. However, they may be harmful to the patients, are expensive, require prolonged times, and can only be carried out in specialised centres. Previously we have reported that about $60 \%$ of patients with occupational asthma from reactive dyes had specific IgE when this was measured by radioallergosorbent test (RAST), ${ }^{57}$ and these results were supported by results of other investigations. ${ }^{2}{ }^{8}$ However, a comparative study of SPTs and the serological measurement of $\operatorname{IgE}$ specific to reactive dye for diagnosis of occupational asthma from reactive dyes is not yet available.

In this study, we compared the diagnostic role of SPTs and the serological measurement 
Table 1 Clinical features of patients with occupational asthma resulting from reactive dyes and asymptomatic or challenge negative control subjects

\begin{tabular}{|c|c|c|}
\hline & $\begin{array}{l}\text { Patients with occupational } \\
\text { asthma from reactive dyes } \\
(n=43)\end{array}$ & $\begin{array}{l}\text { Asymptomatic or } \\
\text { challenge negative } \\
\text { controls }(n=93)\end{array}$ \\
\hline Age $(y)$ & $41.9(8.3)$ & $40.3(8.9)$ \\
\hline Men:women & $31: 11$ & $90: 3$ \\
\hline Atopy to common inhalant allergen $(\%)^{\star}$ & $22(52.4)$ & $30(32.3)$ \\
\hline Mean exposure to reactive dyes ${ }^{\star \star \star}$ (months) & $66.3(59.5)$ & $129.9(63.2)$ \\
\hline \multicolumn{3}{|l|}{ Challenge test to reactive dyes (n (\%)): } \\
\hline Early response & $25(59.5)$ & \\
\hline Late response & $2(4.8)$ & \\
\hline Dual response & $15(35.7)$ & \\
\hline Negative response & - & $5(5.4)$ \\
\hline Asymptomatic exposed workers (n (\%)) & - & $88(94.6)$ \\
\hline
\end{tabular}

${ }^{\star} \mathrm{p}<0.05 ;{ }^{\star \star \star} \mathrm{p}<0.001$

Values in parentheses are SD.

of specific IgE in patients with occupational asthma from exposure to vinyl sulphone reactive dye confirmed by inhalation challenge test.

\section{Methods \\ SUBJECTS}

Forty two patients with occupational asthma resulting from exposure to reactive dyes who had visited our clinic for diagnosis of occupational asthma during the previous 10 years were enrolled. Among them, 39 patients were workers in the factories producing reactive dyes. One patient worked in an iron mill and another two patients in factories that produced automobile tyres, all of which were adjacent to the reactive dye factory. All of the patients with occupational asthma from reactive dyes had this confirmed by bronchial challenge test with causative dyes, such as black GR (33 patients), brilliant orange $3 \mathrm{R}$ (six patients), red $\mathrm{BBN}$ (two patients) and yellow 3R (one patient). They showed early, late, and dual responses in 25 , two, and 15 patients, respectively. Incidence of atopy to the common inhalant allergens was significantly higher in patients with occupational asthma than in the asymptomatic exposed workers $(p<0.05)$. Eighty eight asymptomatic workers in a reactive dye factory and five subjects with negative bronchial challenge to reactive dyes were also enrolled as control subjects exposed to reactive dyes (table 1). Asymptomatic exposed workers were recruited from the three factories that produce reactive dyes. They had worked there for more than 1 year, and their mean (SD) duration of exposure was 129.9 (63.2) months, which was significantly longer than that of patients with occupational asthma from reactive dyes $(\mathrm{p}<0.001)$. Of 93 exposed control workers, 88 participated in the processes of reactive dye production - such as drying, enveloping, mixing, and chemical reaction steps - and another five were office workers. For screening of occupational asthma from reactive dyes at the workplace, we performed a methacholine challenge test according to the method of Chai et al. ${ }^{10}$ Aerosols of $5.0 \mathrm{mg} / \mathrm{ml}$ or $25 \mathrm{mg} / \mathrm{ml}$ of methacholine in saline was inhaled gradually. All asymptomatic subjects showed negative responses to inhalation of the $25 \mathrm{mg} / \mathrm{ml}$ methacholine (no change in forced expired volume in 1 second $\left(\mathrm{FEV}_{1}\right)$ ) and did not have work related respiratory symptoms. Serum samples from all subjects were collected and stored at $-20^{\circ} \mathrm{C}$ until use.

\section{BRONCHIAL CHALLENGE TESTS FOR REACTIVE}

DYES

Bronchial challenge tests for reactive dyes were carried out in the subjects who began to complain of respiratory symptoms after exposure and had methacholine bronchial hyperresponsiveness (concentration $<25 \mathrm{mg} / \mathrm{ml}$ causing a $20 \%$ fall in $\mathrm{FEV}_{1}\left(\mathrm{PC}_{20}\right)$ ). The results of SPTs were not considered when performing bronchial challenge tests. For these tests, we used reactive dye solutions that were dissolved in $0.4 \%$ phenol $/ 0.9 \%$ saline. The solutions were delivered by a Devilbis 646 nebuliser (Devilbis Health Care, Somerset, UK), which was connected to a compressed air source. The patients were asked five times to breath the aerosol up to their vital capacity. Serial increments in concentration of reactive dyes $(0.01,0.1,1.0$, or $2.5 \mathrm{mg} / \mathrm{ml})$ were administered at 10 minute intervals until a $20 \%$ or greater decrease in $\mathrm{FEV}_{1}$ was obtained. We checked the $\mathrm{FEV}_{1}$ of the patients for 8 hours after the inhalation of the aerosol.

\section{SKIN PRICK TESTS}

Skin prick tests were performed with $1 \mathrm{mg} / \mathrm{ml}$ histamine as a positive control, the diluent as a negative control, and two reactive dyes, Remazole black GR (colour index BK-5; Ewha Co, Incheon, Korea), and Remazole orange 3R (colour index O-16; Ewha Co, Incheon, Korea) which have vinyl sulphone reactive groups. Ten $\mathrm{mg}$ of reactive dyes were dissolved in $1 \mathrm{ml} \mathrm{0.4 \%}$ phenol and $0.9 \% \mathrm{NaCl}$ solution ( $\mathrm{pH} 8.0$ ) containing $50 \%$ sterile glycerine. We also performed SPTs with 10 common inhalant allergens-namely, Dermatophagoides farinae, Dermatophagoides pteronyssinus, cat dander, dog dander, cockroach, ragweed, sagebrush, birch, oak, and Aspergillus fumigatus (Bencard, UK). We diagnosed the subjects as atopic when they showed positive SPTs to the common allergens. Positive SPTs were defined as mean diameter of weal larger than $2 \mathrm{~mm}$ more than the negative control and that of an erythema reaction larger than $21 \mathrm{~mm}$.

MEASUREMENT OF SPECIFIC IgE TO VINYL SULPHONE REACTIVE DYES

We measured the specific IgE to reactive dyes with an enzyme linked immunosorbent assay (ELISA). Vinyl sulphone reactive dye was conjugated to human serum albumin (HSA; Dongshin Pharm, Seoul, Korea) by a previously described method. ${ }^{7}$ Reactive dye $(1 \mathrm{mg})$ was dissolved in $1 \mathrm{ml} 2 \%$ HSA in $0.1 \mathrm{M}$ $\mathrm{Na}_{2} \mathrm{CO}_{3}(\mathrm{pH}$ 11). These solutions were stirred at $4^{\circ} \mathrm{C}$ for 18 hours and then dialysed against $0.1 \mathrm{M} \mathrm{Na}_{2} \mathrm{CO}_{3}$ for 48 hours. These reactive dye-HSA conjugates were used for ELISA. Polystyrene microtitre plates (Costar, Cambridge, MA, USA) were coated with $50 \mu \mathrm{l}$ $1: 100$ diluted reactive dye-HSA conjugate in $0.05 \mathrm{M}$ carbonate buffer ( $\mathrm{pH}$ 9.6) for 2 hours at room temperature and overnight at $4^{\circ} \mathrm{C}$. After washing with phosphate buffered salineTween (PBS-T), each well of the microtitre 

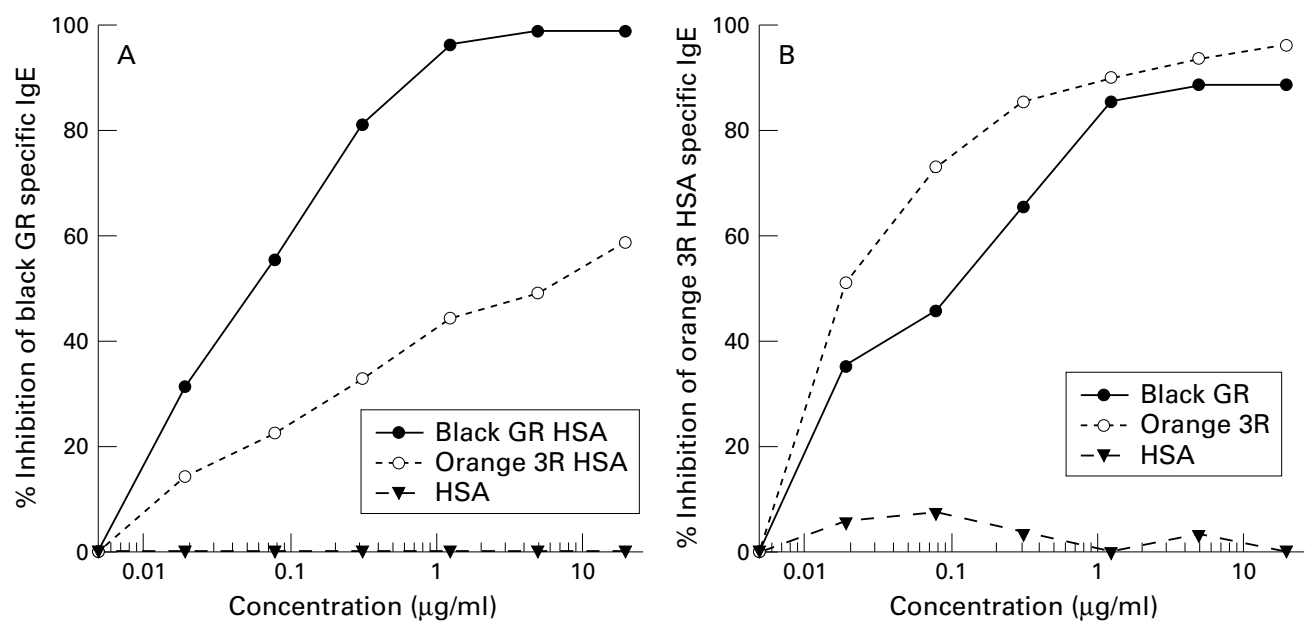

Figure 1 ELISA inhibition curves of (A) IgE specific to black GR conjugated to HSA and (B) IgE specific to orange $3 R$ conjugated to HSA with black GR conjugated to HSA, orange $3 R$ conjugated to HSA, and HSA alone.

plate was blocked by incubation with $200 \mu 11 \%$ bovine serum albumin in PBS-T (137 mM $\mathrm{NaCl}, 1.8 \mathrm{mM} \mathrm{KH} \mathrm{PO}_{4}, 10 \mathrm{mM} \mathrm{Na}_{2} \mathrm{HPO}_{4}, 27$ $\mathrm{mM} \mathrm{KCl}, 0.1 \%$ Tween-20, $\mathrm{pH} 7.4$ ) for 1 hour at room temperature. We incubated $50 \mu \mathrm{l}$ serum from patients in each well for 1 hour at room temperature. After washing three times with PBS-T, $50 \mu 1$ 1:1000 biotin labelled goat antihuman IgE (Vector, Burlingame, CA, USA) was added to each well and incubated for 1 hour. After washing, the wells were incubated with 1:1000 vol/vol streptavidin-peroxidase (Sigma, St Louis, MO, USA) for 30 minutes before another washing step. The colorimetric reaction was developed with $50 \mu \mathrm{l}$ ABTS solution (25 mg 2,2-azino-bis-3-ethylbenzthiazoline-sulfonic acid in $50 \mathrm{mM}$ citrate phosphate buffer, $50 \mu \mathrm{l} 30 \% \mathrm{H}_{2} \mathrm{O}_{2}$ ) for 5 minutes. The reaction was stopped by the addition of 50 $\mu l \quad 2 \quad \mathrm{NaN}_{3}$, and optical density (OD) measured at $410 \mathrm{~nm}$ by an automated spectrophotometer for ELISA (Dynatec, Alexandria, CA, USA). All assays were performed in duplicate.

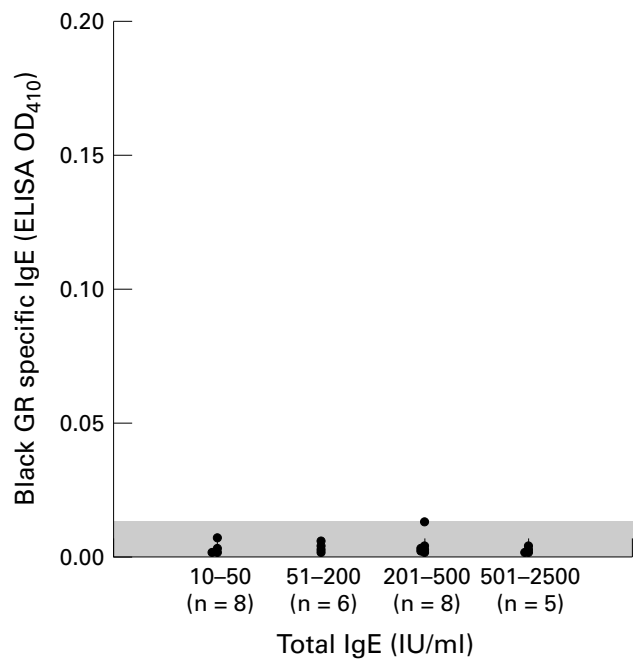

Figure 2 IgE specific to black GR conjugated to HSA was not detected in non-sensitised patients with high serum IgE concentrations. Shaded area indicates the negative criteria of IgE specific to conjugated black GR $(<0.014)$.
ELISA INHIBITION OF IgE SPECIFIC TO BLACK GR For ELISA inhibition, the 1:4 diluted pooled serum samples with a high concentration of black GR and orange $3 R$ specific $\operatorname{IgE}(n=4)$ were preincubated with different concentrations $(20 \mathrm{mg} / \mathrm{ml}, 5 \mathrm{mg} / \mathrm{ml}, 1.25 \mathrm{mg} / \mathrm{ml}, 0.31$ $\mathrm{mg} / \mathrm{ml}, 0.078 \mathrm{mg} / \mathrm{ml}, 0.019 \mathrm{mg} / \mathrm{ml}$, and 0.005 $\mathrm{mg} / \mathrm{ml}$ ) of black GR in HSA, orange $3 \mathrm{R}$ in HSA, and HSA alone overnight at $4^{\circ} \mathrm{C}$. Of the preincubated pooled serum samples, $50 \mu \mathrm{l}$ was added to the well coated with reactive dye in HSA for 1 hour. The ELISA OD of IgE specific to reactive dye in HSA in preincubated pooled serum samples was measured as already described.

CLINICAL VALIDATION OF SPTS AND ELISAS FOR SPECIFIC IGE TO REACTIVE DYES

Clinical sensitivity and specificity were assessed by the fraction of positive skin prick tests among patients with positive challenge to reactive dyes and the fraction of negative skin prick tests among the asymptomatic patients with negative challenge to reactive dye. The positive predictive and negative predictive values were assessed by the fraction of patients with positive challenge to reactive dyes among the subjects with a positive skin prick test and asymptomatic subjects with a negative challenge to reactive dyes among the subjects with a negative skin prick test.

STATISTICAL ANALYSIS

Independent $t$ tests were applied to evaluate the differences in ELISA OD and weal sizes between the group with occupational asthma resulting from reactive dyes and the exposed control group. For analysis of correlation between the results from SPTs and ELISAs and the changes of ELISA OD values, we used Pearson's correlation analysis and the MannWhitney $U$ test, respectively.

\section{Results}

SPECIFICITY OF THE ELISA MEASUREMENT OF IgE SPECIFIC TO HSA REACTIVE DYE CONJUGATES The ELISA OD values of IgE specific to black GR conjugated to HSA and orange $3 \mathrm{R}$ conjugated to HSA in pooled serum samples of 
patients with occupational asthma from reactive dyes $(n=4)$ were 0.653 and 0.249 . The specific IgE to black GR was dose dependently inhibited with both conjugates (fig $1 \mathrm{~A}$ ). However, the $50 \%$ inhibitory concentration of black GR conjugated to HSA was about 100 times lower than that of the orange $3 \mathrm{R}$ conjugate $(0.05 \mu \mathrm{g} / \mathrm{ml} v 5.0 \mu \mathrm{g} / \mathrm{ml})$ and the maximum inhibitory percentage of conjugated black GR was higher than that of conjugated orange $3 \mathrm{R}$ $(98.7 \%$ v $58.4 \%)$. The IgE specific to orange $3 \mathrm{R}$ conjugated to HSA was also dose dependently inhibited by both black GR and orange $3 \mathrm{R}$ conjugates (fig $1 \mathrm{~B}$ ). The $50 \%$ inhibitory concentration of conjugated black GR was about five times higher than that of conjugated orange $3 \mathrm{R}(0.1 \mu \mathrm{g} / \mathrm{ml} v 0.02 \mu \mathrm{g} / \mathrm{ml})$ and their maximal inhibition \% was similar $(88.8 \%$ v $96.4 \%)$. IgEs specific to both conjugated black GR and orange $3 R$ were not inhibited with HSA alone. IgE specific to conjugated black GR was not detected with ELISA in the serum

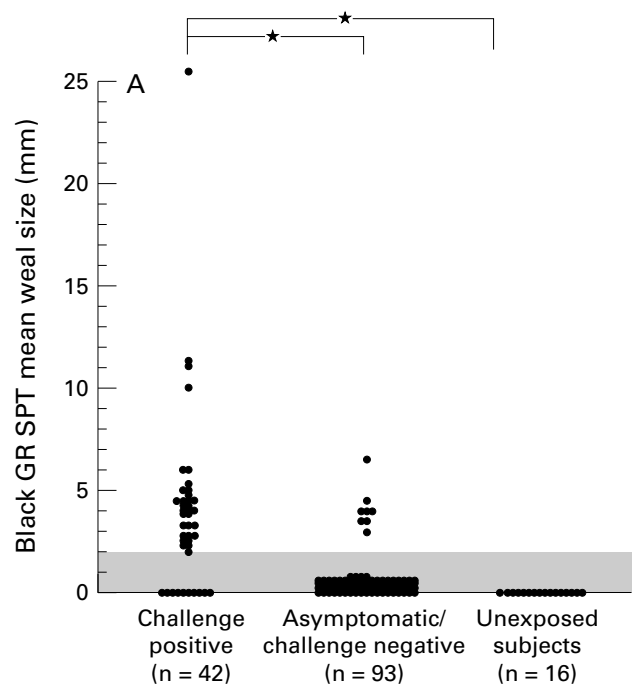

samples from subjects unexposed to reactive dyes with variable ranges of total IgE (fig 2).

RESULTS OF SPTS AND ELISAS OF IgE SPECIFIC TO REACTIVE DYES

Thirty two patients with occupational asthma from reactive dyes $(76.2 \%)$ and eight control subjects exposed to reactive dyes $(8.6 \%)$ had positive responses to reactive dyes in SPTs. None of the 16 control subjects not exposed to reactive dyes had (fig 3). The incidence of positive SPTs was significantly higher in the group with occupational asthma from reactive dyes $(p<0.001)$. We also measured IgE specific to conjugated black GR and orange $3 R$ with ELISAs. The mean (SD) values of ELISA OD of IgE specific to black GR and orange $3 R$ conjugates in unexposed non-atopic subjects were 0.004 (0.003) and 0.001 (0.003), respectively. We considered that IgEs specific to black GR or orange $3 R$ were present when the OD

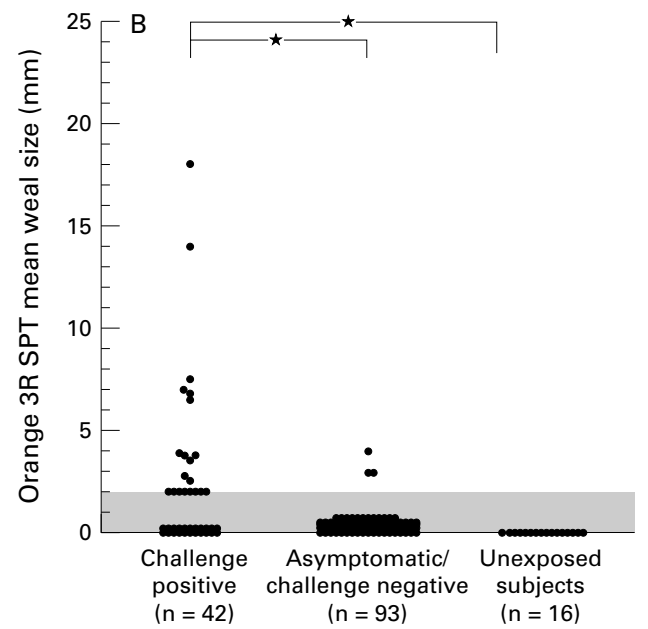

Figure 3 Mean SPT weal size to $(A)$ black $G R(10 \mathrm{mg} / \mathrm{ml})$ and $(B)$ orange $3 R(10 \mathrm{mg} / \mathrm{ml})$ in the patients with occupational asthma resulting from exposure to reactive dyes, controls exposed to reactive dyes, and unexposed control subjects. ${ }^{*} p<0.001$.
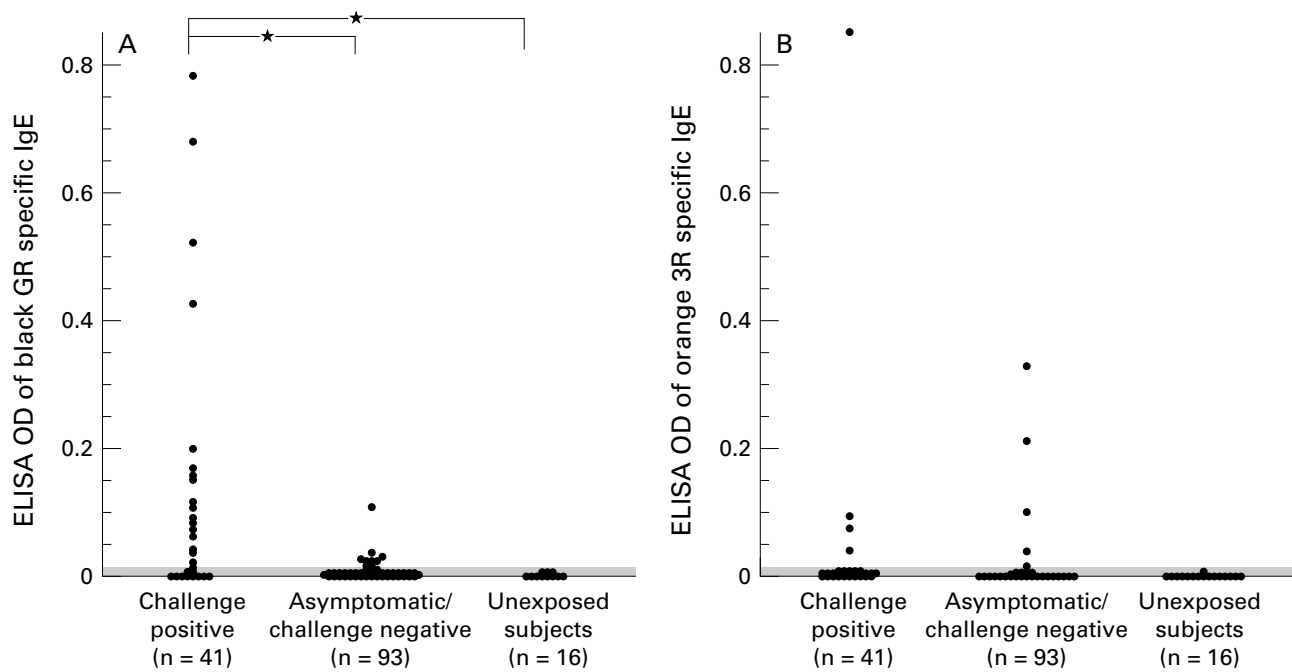

Figure 4 ELISA OD values to the IgE specific to (A) black GR conjugated to HSA and (B) orange $3 R$ conjugated to $H S A$ in the patients with occupational asthma from reactive dyes, subjects exposed to reactive dyes, and unexposed control subjects. ${ }^{\star} p<0.001$. 


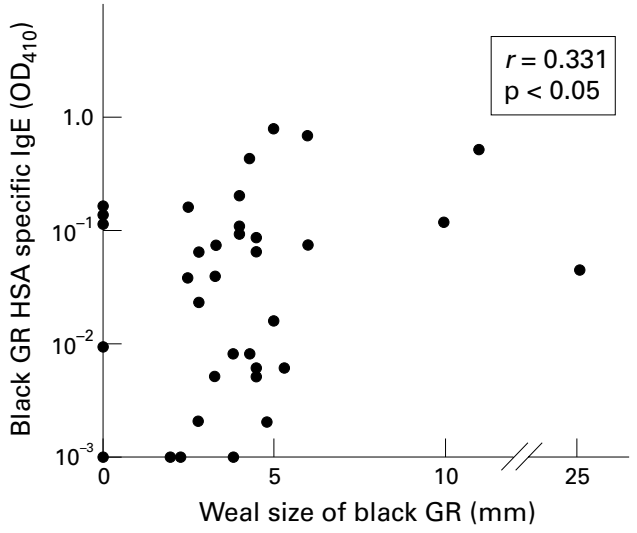

Figure 5 Correlation between ELISA OD values and mean SPT weal sizes to the black GR in patients with occupational asthma from reactive dyes $(n=41)$.

value was higher than 0.013 . With these criteria, we detected specific IgE to reactive dyes conjugated to HSA in $22(53.7 \%)$ of 41 patients with occupational asthma from reactive dyes and in 10 asymptomatic subjects or subjects with negative SPT challenge $(10.8 \%$, fig 4). There was a weak correlation between the mean weal sizes of black GR in SPTs and the ELISA OD of IgE specific to conjugated black GR in 41 patients with occupational asthma from reactive dyes (fig 5).

We could detect specific IgE to reactive dye with SPTs or ELISAs in 51 out of 135 patients with occupational asthma from reactive dyes or asymptomatic controls exposed to reactive dyes. Among the patients with IgE specific to reactive dyes, $52.4 \%$ were sensitised to common inhalant allergens. Sixteen subjects from 93 controls exposed to reactive dyes had $\operatorname{IgE}$ specific to reactive dyes detected by SPT or ELISA, and their mean duration of exposure to the reactive dyes was 160.3 (21.7) months

SENSITIVITY, SPECIFICITY, POSITIVE PREDICTIVE VALUES, AND NEGATIVE PREDICTIVE VALUES OF SPT AND ELISA FOR THE DIAGNOSIS OF OCCUPATIONAL ASTHMA FROM REACTIVE DYES For calculation of the sensitivity, specificity, negative predictive values, and positive predictive values of the SPTs and ELISAs, we assumed that the group positive for bronchial challenge was the true positive, and the asymptomatic group negative to challenge was the true negative group. The sensitivity $(76.2 \% v$ $53.7 \%)$, specificity $(91.4 \%$ v $86 \%$ ), positive predictive value $(80 \% \mathrm{v} 62.9 \%)$, and negative predictive value $(89.5 \%$ v $80.8 \%)$ of SPTs were higher than those of the ELISAs. However, in four patients with occupational asthma from reactive dyes and eight control subjects exposed to reactive dyes, we detected IgE specific to reactive dyes with ELISAs, even

Table 2 Sensitivity, specificity, positive predictive value, and negative predictive values of SPTs, ELISA, and combined SPTS and ELISAs

\begin{tabular}{lllll}
\hline & $\begin{array}{l}\text { Sensitivity } \\
(\%)\end{array}$ & $\begin{array}{l}\text { Specificity } \\
(\%)\end{array}$ & $\begin{array}{l}\text { Positive predictive } \\
\text { value (\%) }\end{array}$ & $\begin{array}{l}\text { Negative predictive } \\
\text { value (\%) }\end{array}$ \\
\hline SPTs & 76.2 & 91.4 & 80.0 & 89.5 \\
ELISAs & 53.7 & 86.0 & 62.9 & 80.8 \\
Combined SPTs and ELISAs & 83.3 & 82.8 & 68.6 & 91.7 \\
\hline
\end{tabular}

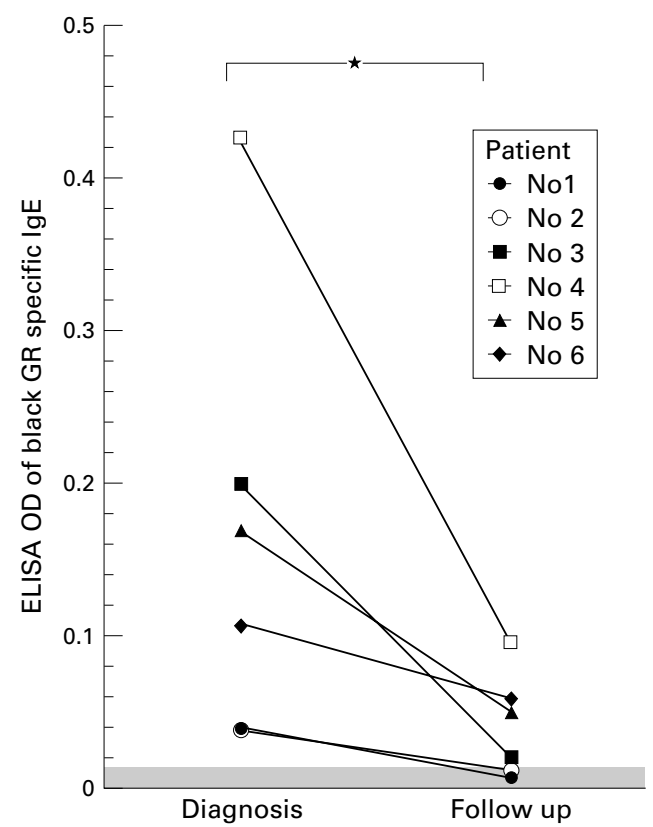

Figure 6 Changes of values of ELISA OD to IgE specific to black GR conjugated to HSA after avoidance in six patients with occupational asthma from reactive dyes, ${ }^{\star} p<0.05$.

though they had negative responses to SPTs. When the results of SPTs and ELISAs were combined, the sensitivity and negative predictive value of the diagnosis of occupational asthma from reactive dyes were increased to $83.3 \%$ and $91.7 \%$, respectively (table 2 ).

CHANGES OF IgE SPECIFIC TO BLACK GR AFTER AVOIDANCE OF REACTIVE DYES

We compared the specific IgE to black GR in six patients who had avoided exposure to reactive dyes for 51 months (patient 1), 18 months (patient 2), 33 months (patient 3), 31 months (patient 4), 12 months (patient 5), and 20 months (patient 6). Their mean (SD) duration of avoidance was 27.8 (10.3) months. At the time of diagnosis, IgE specific to black GR was detected in all six patients and their ELISA OD values for that IgE were markedly decreased by avoidance $(p<0.05$, fig 6$)$.

\section{Discussion}

Serological measurement and SPTs for IgE specific to reactive dyes have been used for diagnosis of occupational asthma from reactive dyes. ${ }^{1-8}$ We performed SPTs and ELISAs with two vinyl sulphone reactive dyes and found cosensitisation to these dyes in some patients with occupational asthma from reactive dyes. Previously, we had also reported the presence of cross reactivity between Remazole black GR conjugated to HSA and Remazole brilliant orange $3 \mathrm{R}$ conjugated to HSA, and their chemical structures are similar to each other. ${ }^{7}$ In this study, we found that $83.3 \%$ of patients with occupational asthma from reactive dyes had positive results to SPTs or ELISAs or both. This result was consistent with other studies ${ }^{2}{ }^{8}$ and suggested that both SPTs and ELISAs would be valuable in the diagnosis of occupational asthma from reactive dyes. However, the 
sensitivity, specificity, positive predictive value, and negative predictive value of the SPTs were higher than those of the ELISAs. We performed SPTs with $10 \mathrm{mg} / \mathrm{ml}$ reactive dye in $0.4 \%$ phenol $/ 0.9 \%$ saline, but other investigators have used reactive dyes conjugated to HSA for the skin prick test. ${ }^{2}$ In this study, we detected the IgE specific to reactive dye conjugated to HSA with ELISA in four patients with occupational asthma from reactive dyes who had negative skin responses and we had already reported one case of occupational asthma from reactive dyes in a patient who showed a dual response to the reactive dye-HSA conjugate but not to the unconjugated reactive dye solution. ${ }^{9}$ These results suggest the possibility that the reactive dye-HSA complex may have a greater diagnostic value than reactive dye alone for SPTs. However, a comparative study did not show a significant difference in the clinical usefulness of SPTs between reactive dye-HSA conjugate and unconjugated reactive dye agents. ${ }^{8}$ We have also compared the skin response with reactive dye alone and reactive dye conjugated to HSA in some patients with occupational asthma from reactive dyes and asymptomatic workers and could not find any significant differences in skin responsiveness between the two extracts. However, we could not compare the skin reactivity of the two extracts in the four subjects who showed positive results only to the ELISA.

The IgE epitopes of reactive dye-carrier protein are not yet clarified. The vinyl sulphone reactive dyes easily form covalent or noncovalent bonds with soluble autologus proteins ${ }^{11}$ and our good SPT results to reactive dye alone suggested that vinyl sulphone reactive dyes are very rapidly attached to carrier proteins. Although HSA is the most predominant extravascular protein and the allergenicity of the reactive dye-HSA complex is better than other reactive dye-carrier protein complexes, ${ }^{6}$ the possibility that the complexes of reactive dyes and other carrier proteins have different IgE epitopes cannot be excluded. ${ }^{36}$ The reactions forming haptens are also markedly influenced by $\mathrm{pH}$, temperature, and the molar ratios of reactive dye to the carrier proteins, ${ }^{312} 13$ and these factors may cause differences in the conformations of the complex. Hence we thought that unconjugated reactive dye might have advantages in some patients with occupational asthma from reactive dyes and complement the ELISAs which used the reactive dye-HSA conjugates. The discrepancy between the SPTs and ELISAs in 11 patients with occupational asthma from reactive dyes (four and seven patients with occupational asthma from reactive dyes were exclusively positive to ELISA and SPT, respectively) suggests heterogeneity of allergenic determinants of the reactive dye-carrier protein.

The values of the ELISA OD of IgE specific to reactive dyes were decreased after avoidance of reactive dyes and this result was also consistent with the previous report. ${ }^{2}$ Thus it is possible that the specific IgE may not be detected in some patients who had already left the factory before diagnosis. Our study also showed that the serological measurement of specific $\operatorname{IgE}$ would be very useful not only for screening and diagnosis, but also for monitoring patients. As the reactive dyes could be widely spread by wind during the production process, strict avoidance might be very important for treatment of occupational asthma from reactive dyes. Serological measurement of specific IgE to reactive dye would be a useful indicator with which to monitor the adequacy of the avoidance. The IgE specific to reactive dye could be detected in some workers in neighbouring factories ${ }^{14}$ and three patients with occupational asthma from reactive dyes in this study, with strong skin reactivity and high ELISA OD to reactive dyes, were from this group. For these patients, it would be difficult to consider occupational asthma from reactive dyes without the results of SPTs.

From these results, we think that the SPTs and ELISAs may be valuable tools for screening, diagnosis, and monitoring occupational asthma resulting from exposure to reactive dyes; these two tests might complement each other for such a diagnosis.

This study was supported by a Yonsei University College of Medicine, Internal Medicine Research grant.

1 Stern MA. Occupational asthma from a reactive dye [abstract]. Ann Allergy 1985;55:264

2 Docker A, Wattie JM, Topping MD, et al. Clinical and immunological investigations of respiratory disease in workers using reactive dye. Br F Ind Med 1987;44:534-41.

3 Luczynska CM, Topping MD. Specific IgE antibodies to reactive dye albumin conjugates. F Immunol Methods 1986; 85:177-86.

4 Park HS, Kim YJ, Lee MK, et al. Occupational asthma and specific IgE antibodies to reactive dyes. Yonsei Med F 1989; 30:298-304

5 Park HS, Lee MK, Hong CS. Specific antibodies to black GR HSA conjugates in occupational asthmatic patients to reactive dye, black GR. Fournal of the Korean Medical Association 1989;32:1197-205.

6 Wass U, Nilsson R, Nordinder R, et al. An optimized assay of specific IgE antibodies to reactive dyes and studies of immunologic responses in exposed workers. F Allergy Clin Immunol 1990;85:642-8.

7 Park HS, Lee MK, Kim BO, et al. Clinical and immunologic evaluation of reactive dye-exposed workers. f Allergy Clin Immunol 1991;87:639-49.

8 Nilsson R, Nordlinder R, Wass U, et al. Asthma, rhinitis, and dermatitis in workers exposed to reactive dyes. $\mathrm{Br} \mathcal{F}$ Ind Med 1993;50:65-70

9 Hong CS, Park HS. Heterogeneity of IgE antibody response to reactive dye in sera from four different sensitized workers. Clin Exp Allergy 1991;22:606-10.

10 Chai H, Farr RS, Froelich LA, et al. Standardization of bronchial inhalation challenge procedure. F Allergy Clin Immunol 1975;56:323-7.

11 Shore J. Mechanism of reaction of proteins with reactive dyes III: reactivity of soluble proteins with chlorotriaxine dyes. fournal of the Society of Dyers and Colourists 1968;84:545-55.

12 Hille E. Über die einwirkung von reactivfarbstoffen auf wolle. Textile Praxis 1962;17:171-7.

13 Shore J. Mechanism of reaction of proteins with reactive dyes II-reactivity of simple model compounds with chlororiazine dyes. Fournal of the Society of Dyers and Colourists 1968;84:413-22.

14 Park HS, Kim JW, Hong CS. The prevalence of specific IgE and IgG to reactive dye-human serum albumin conjugate in workers of a dye factory and neighboring factories. $\mathcal{F}$ Korean Med Sci 1992;6:63-8. 